\title{
Comparative Public Health: The Political Economy of Human Misery and Well-Being
}

\author{
HAZEM AdAM GHOBARAH \\ Harvard University and Mathsoft \\ Paul Huth \\ University of Michigan
}

BRuce RusSETT

Yale University

\begin{abstract}
Nearly 10 percent of the world's economic resources are devoted to health care. But why do certain countries devote more resources to public health? Why are some countries better than others at achieving tangible health outcomes using the same level of economic resources? Surprisingly, political scientists and public health scholars have done only limited systematic research on these important questions. We address them by developing and testing an analytical framework of domestic and international political influences on public health. We use new data from the World Health Organization to examine cross-national variation first in the level of public expenditures on health, and then in the level of achievement of health outcomes. We measure these influences and their relative impact in terms of dollars and years of health, respectively. Dictatorship, severe income inequality, ethnic heterogeneity, and persistent international hostilities substantially depress the amount of public resources allocated to health care. Moreover, we analyze the extent to which, given the same level of resources allocated to public health, overall national health performance suffers further from unequal provision of services, rapid urbanization, and civil conflict.
\end{abstract}

The health of humanity varies enormously: by genetic endowment, environmental conditions, and access to health care; by age, gender, income level, and country (Gakidou and King, 2002). Some people live long healthy lives in peace and affluence; many others' lives are briefer and burdened by major disabilities from disease or injury, and often the characterization "nasty, brutish, and short" is all too apt. Our central claim in this article is that politics plays an important role in influencing public health conditions, but unfortunately political scientists and other scholars have only conducted limited systematic research on the topic (e.g., Moon,

\footnotetext{
Author's note: We thank the Weatherhead Initiative on Military Conflict as a Public Health Problem, the Ford Foundation, and the World Health Organization for financial support and Gary King, Lisa Martin, and Ben Valentino for helpful comments.
} 
1991; Przeworski, Alvarez, Cheibub, and Limongi, 2000; Price-Smith, 2002). As a result, the existing literature on the comparative cross-national analysis of the determinants of public health performance is largely based on the work of economists and public health experts (Filmer and Pritchett, 1999; Evans, Tandon, Murray, and Lauder, 2000a) in which political processes and conditions are understudied. We believe that political scientists can contribute substantially to a better understanding of why public health conditions vary in systematic ways across countries.

We develop and then test an analytical framework of domestic and international political influences on human misery and well-being. Drawing on newly developed cross-national measures of public health from the World Health Organization (WHO), we find strong evidence that cross-national variation in public health performance is shaped by a variety of political forces, including democracy, civil wars, international rivalries, and political inequalities resulting from ethnic cleavages and disparities in wealth. We hope to help broaden the research agenda of comparative and international relations scholars by encouraging further systematic cross-national analyses of the determinants of human misery and wellbeing. Indeed, our larger objective is to focus the attention of both social science and public health on these influences, in the hope of stimulating critical analyses to refine the findings we report here. ${ }^{1}$

\section{What Is to Be Explained?}

Previous work in political science has concentrated on measures of mortality, as these have been the only data available for most countries. Davis and Kuritsky (2002) report that severe military conflict in sub-Saharan Africa cut life expectancy by more than 2 years and raised infant mortality by 12 per thousand. In a global sample, Zweifel and Navia (2000) find democracies have an infant mortality rate about 10 per thousand below that of comparable non-democracies. Przeworski et al. (2000:241) report the same difference in infant mortality rates, and a gap of about 5 years in life expectancy. Similarly, Lake and Baum (2001) find substantial differences in both measures, as well as in measures of citizens' access to health resources related to both contemporaneous comparison of regimes and changes in regimes over time.

In this article we use new data compiled by the WHO that are more comprehensive and more reliable than information on life expectancy and infant mortality rates. The unit of analysis is the nation-state, since our interest is in the systemic and institutional influences that are characteristic of national political systems. Many of our explanatory variables reflect the characteristics of institutions of the whole society (e.g., regime type, level of expenditure on health, the experience of civil war or international security threats) and in some degree affect virtually all its members. But we also examine the effects on the average level of health conditions in the society stemming from the distribution of income within states, their ethnic heterogeneity, urbanization, and levels of education. Some (e.g., regime type) are obviously political variables, but all reflect the political power - or lack of it - of various groups and their ability to secure better health through public and private resources.

Our principal analysis is to explain outputs of the health system across countries, as expressed by WHO's measure of overall health-Health Adjusted Life Expectancy (HALE) - for the year 2000. It discounts total life expectancy at birth in each country by the number of years the average individual spends with a major disability as the burden of disease or injury - the gap between total life expectancy

\footnotetext{
${ }^{1}$ In this we respond to the call of King and Murray (2002) for systematic analysis of human misery. Also see Russett (1978) and Pritchett and Summers (1996).
} 
and expected years without disability. It is estimated from three kinds of information: the fraction of the population surviving to each age level (calculated from birth and death rates), individual-level data on the incidence and prevalence of various diseases and disabilities at each age, and the weight assigned to debilitation from each type of condition. The result is the proportion of the population suffering from disabilities, giving the average number of years of healthy life that a newborn could expect to live.

The measure taps the concept of years of healthy and productive life, and so is expressed in intuitively meaningful units. It varies substantially by region of the world and income level. In rich countries, more disabilities are associated with chronic conditions of old age - and, at that point, relatively short life expectancies. By contrast, in poor countries infant mortality is far higher and many health problems derive from the burden of infectious diseases like malaria and schistosomiasis, carried by children who may live a long time with seriously impaired health and quality of life. Empirically, the share of simple life expectancy lost to disability varies from under 9 percent in the healthiest regions of the world to over 14 percent in the least healthy ones (WHO, 2000:28). Adjusting life span by time spent with disability comports with psychological findings that people do not simply seek long life, but sharply discount the value of years at the end of life spent with major physical and psychological disabilities (Diener, Wirtz, and Oishi, 2001).

This information-intensive measure requires not just vital registration data for births and deaths, but expensive health surveys of death, disease, and disability by age and gender. While widely used for monitoring and forecasting in the United States (see, e.g., Cutler and Richardson, 1997), data only began to be collected on a global basis by WHO for the year 1990 (Murray and Lopez, 1996), with the most comprehensive report being its 1999 and 2000 surveys (WHO, 2000). Life tables for 2000 for all 191 WHO members were developed from surveys that were supplemented by censuses, sample registration systems, and epidemiological analyses of specific conditions. WHO experts provided estimates of their degree of uncertainty about the data's accuracy, subjected it to a variety of statistical tests for incompleteness and bias, and adjusted it accordingly. Then they estimated disease-specific disability rates for all countries within each of 14 regions of the world defined geographically and epidemiologically, and used these to adjust available data on death rates at different age levels and life expectancy for each country (Mathers, Sadana, Salomon, Murray, and Lopez, 2000). The index - of expected healthy life years (i.e., disability-free life) - ranges from 73.8 (Japan) to 29.5 (Sierra Leone), with a median of 58.5 (Syria).

Our analyses must be cross-sectional, as adequate time-series data do not exist on a global basis. Causal inference must thus be somewhat tentative, but still is possible with careful theory and the use of appropriate lags for the independent variables. While limitations of these data must be borne in mind, they are the best that have ever been available, and do permit us to make systematic inferences about the influences on health conditions across countries (see, e.g., Filmer and Pritchett, 1999:1312; Williams, 1999; Murray and Lopez, 2000).

\section{Theoretical Framework}

To understand why there is so much cross-national variation in human misery and well-being we build upon existing theory and evidence regarding the influence of a variety of economic and social variables by systematically examining political variables. While the long-term goal of our theoretical and empirical research is to understand the potentially wide-ranging set of complex causal connections that shape public health, in this article we take a first step in that direction by breaking down our analysis into two stages. 
First, we address political influences on the allocation and total spending of resources devoted to improving the health of the population. These are key variables for explaining health conditions in a country, and so warrant attention to determine what influences help produce relatively high health spending. The amount of resources devoted to health is determined both by the total resources available in the economy and by public and private allocation decisions on how much of the resources to spend on health care. Given our focus on political determinants, we pay particular attention to governments' decisions to allocate financial resources to public health expenditures. Then we investigate what affects a health system's effectiveness at using the resources allocated to it, or "productivity." These influences include not only the level of health expenditures, but also social and political factors that influence what particular health conditions are targeted and which segments of the population are the greatest beneficiaries of services provided by the health care system. Figure 1 summarizes our conceptual framework.

We begin by discussing the general relationships between politics and health, and then elaborate testable hypotheses for more specific causal connections linking political variables to public health. In broad theoretical terms we identify four major influences on public health in societies and that political conditions and processes in turn are important causes of each of these major influences on health. In summary, we argue that public health conditions are shaped by the interplay of exposure to conditions that create varying risks of death and disease for different groups in society and the ability of groups in society to gain access to health care and therefore receive the full range of benefits produced. A country's health performance reflects its particular political struggles and competition over investment and resource decisions regarding health care and over the distribution of health care.

1) The exposure of populations to the risk of death, disease, and disability. Different populations across and within countries are exposed in different degrees. Geography and levels of development are basic factors to consider. People in tropical climates are at greater risk of many infectious diseases. In poor countries

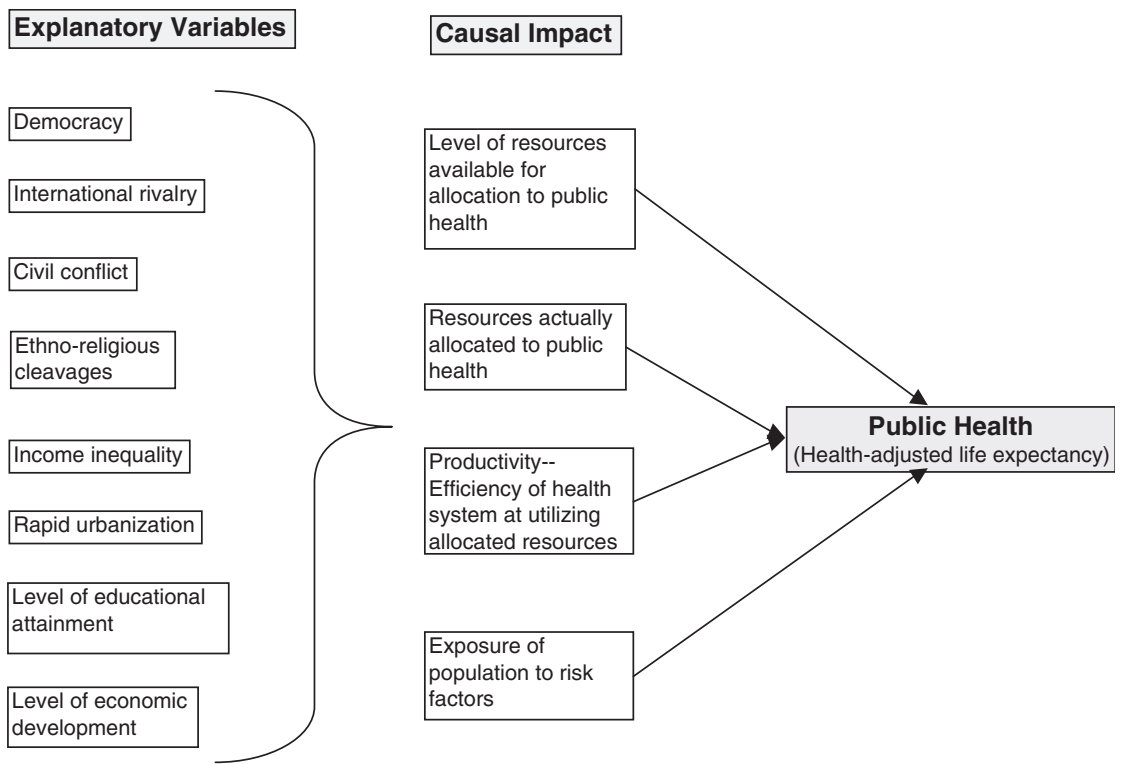

FIG. 1. Conceptual Framework for Studying the Impact of Political, Economic, and Military Factors on Public Health. 
much of the population lives in rural areas where access to good health care is generally lower than in cities. As a result, preventive care is less available and treatment of disease and injury is less extensive and effective. At the same time, health care systems can suffer in large urban areas experiencing rapid growth with the result that some urban populations are at great risk for many health problems (Shah, 1997; Garrett, 2001; Szreter, 2001). Political institutions and practices, however, can raise or lower health risks by influencing access to public services. Differential political influence plays a crucial role in determining who has full or limited access to health benefits. For example, income inequalities often translate into political inequalities, with the health needs of low-income groups neglected relative to those of richer groups (Moon, 1991; Moon and Dixon, 1992; Wilkinson, 1996; Foege, 2000:7). When political conflicts escalate to large-scale violence they expose civilians to great health risks due to direct attack, dislocation, and the destruction of public health infrastructure.

2) The financial and human resources available for addressing public health needs. Higher levels of income and wealth provide a larger pool of financial and human resources to draw upon. Public and private actors can spend more on health care needs and to develop and purchase more advanced medical technologies. A larger pool of financial resources will enable greater investments in human resources; that is, training more doctors and health specialists. Irregular transfers of political power and political unrest in undemocratic systems reduce growth rates (Przeworski et al., 2000:ch. 4), and hence the pool of financial resources for health care.

3) The level of resources actually allocated to public health needs by the private and public sectors. Public health analysts consistently argue that education levels in society affect public health (e.g., Sen and Dreze, 1999; Evans et al., 2000a). A more educated population is likely to be more knowledgeable of health risk factors, to support greater investment and expenditure, and to utilize health care services. But claims to resources for public health compete with other demands, and politics can prove crucial in deciding which resources are actually allocated. Below we hypothesize that leaders in democratic countries have greater political incentives to invest in collective goods such as public health care. We also consider how international security threats create pressures for government leaders to allocate more resources to military and defense capabilities, at the expense of non-defense needs such as public health.

4) The degree to which resources actually allocated to public health are efficiently utilized. Politics can influence efficiency in two ways. Public health services may not be directed to groups with the greatest need. Poor urban residents, low-income groups, and ethnic minorities are often at greater risk of health problems, yet less effectively represented in the political competition for scarce resources. Health care services for these politically marginalized groups are skewed in favor of wealthy segments of the population or dominant ethnic groups who on average are healthier and less at risk. Second, health systems often become less efficient during wartime (due to shortages of doctors, displaced populations, and the destruction of the health care infrastructure), and these inefficiencies are likely to persist into the postwar period as well.

The first stage in understanding differences in public health conditions across countries begins with the influences on the level of public expenditures devoted to health care. Since the choice to allocate public resources to health care is fundamentally a political one beyond pure availability of resources in the whole economy, we must know what affects that choice. We then show that allocation decisions concerning public health spending are important to explaining the overall level of resources devoted to the health system on a per capita basis. Total health expenditure per capita, in turn, becomes a critical variable to explain health outputs, notably HALE. 
To analyze health expenditures we use WHO data that began with IMF and national sources, supplemented by national accounts data from UN and OECD sources and household surveys and WHO estimates (Pouillier and Hernandez, 2000). Since our first step concerns the government decision to allocate budgetary expenditures to health care, the dependent variable for this equation is public health expenditures as a percent of GDP for 1997 (WHO, 2001). It ranges from $0.1 \%$ in Zaire (Congo) to $8.1 \%$ in Germany with a median of $2.7 \%$ (Albania).

\section{Explaining the Allocation of Resources to Public Health}

We begin with hypotheses concerning domestic politics.

\section{H1: Higher levels of democracy will result in state leaders allocating more expenditures to public health.}

Political leaders want to retain power. They must form a winning coalition among the politically active. To do so they distribute private goods to their supporters, and provide collective goods widely for the population. All leaders provide both private and collective goods in some degree. But since democratic leaders must satisfy a wider range of supporters they are less able than authoritarian ones to extract rents for the private benefit of small groups, and must respond more to broad demands for public well-being (Olson, 1993; Bueno de Mesquita, Morrow, Siverson, and Smith, 1999; Lake and Baum, 2001). They are more likely to invest in public goods such as health services because populations will hold them accountable for failing to address basic and pressing health care problems. For example, famines are much more common in authoritarian states (Sen, 1981), which spend less to prevent them or to relieve their consequences. Przeworski and colleagues (2000:239) report that the strong effect of democracy in lowering infant mortality operates largely through health expenditures (see also Dasgupta, 1993 and Moon, 1991:ch. 6).

Political system type is measured by the Polity IV average score for 1996 and 1997, from (www.bsos.umd.edu/cidcm/polity/). For the 22 countries in our sample with no Polity score we imputed a regime score from Freedom House scores (www.freedomhouse.org/ratings/index.htm), which correlate highly $(\mathrm{r}=.95)$ with Polity where both exist. Following common practice (e.g., Maoz and Russett, 1993) we create a 21-point index for each state from a scale for degree of autocracy ranging from -10 (most autocratic) to 0 (least autocratic) and one for degree of democracy from 0 (least democratic) to +10 (most democratic), and then produce the composite index by summing the two components. This scale, which we treat as interval, varies from -10 (e.g., North Korea, Myanmar) to + 10 (e.g., Japan, Norway), with a median of 7 (e.g., Ukraine).

H2: Higher levels of income inequality in society will result in state leaders allocating fewer expenditures to public health.

High income inequality indicates a greater ability of economically privileged groups to influence the political system for their own benefit rather than that of the majority. Many public health care programs are directed at basic health services for poor and disadvantaged groups. They are of little direct value to wealthier segments of the population, who rely more on private health care and more specialized forms of public health services. Thus political pressure from economically powerful groups diverts state expenditures away from basic universal health care.

Our measure is the Gini index of inequality of income distribution in 1997. This index, derived from a Lorenz curve of the actual distribution of household income, represents the area between the curve and the 45-degree line for a totally equal income distribution. The data begin with World Bank estimates for 111 countries, supplemented by WHO's multiple imputation estimates using information on 
socioeconomic development and life expectancy at birth (Evans, Bendib, Tandon, Lauer, Ebenezer, Hutubessy, Asada, and Murray, 2000b; an early effort is Russett, Jackson, Snidal, and Sylvan, 1981). Theoretically the Gini index ranges from zero (complete equality) to 1.00 (one person has it all); in practice our national Gini indices range from a very equal .187 (Slovakia) to .609 (Sierra Leone), with a median of .374 (Uganda).

\section{H3: Higher levels of racial/linguistic/religious diversity in society will result in state leaders allocating fewer expenditures to public health.}

Differences in the ethnic and racial makeup of a country's population can be a source of political conflict that produces various forms of discrimination and unequal access to political power (see, e.g., Gurr, 2000). Political inequality in turn skews the distribution of resources devoted to public policy programs, including health care. Minorities suffering from discrimination are likely to be in greater need of basic health services but in a weak political position to press for them effectively. Dominant ethnic groups seek to limit public health expenditures for which minorities could be primary beneficiaries and to instead try and shift resources into other state programs that are of greater benefit to them. Overall, public health expenditures will reflect the political weakness of groups discriminated against, and thus will be lower than in more homogenous populations.

We use Vanhanen's (1999) index of racial-linguistic-religious heterogeneity. This index, stable over moderate time periods, measures the percentage of the largest ethnic group identified by each of these three criteria, giving each equal weight by summing the three percentages and subtracting the sum from 300 (a completely homogeneous state by all three criteria). It is conceptually somewhat different from that of Gurr (1993), when logged correlating with an $r$ of .69 with Gurr's index. But it was created with Gurr's effort in mind and covers more countries. It ranges from 177 (Suriname, very heterogeneous) to a low of 0 (North Korea, complete homogeneity), with a median of 38 (Uzbekistan). The index is skewed, so we use its natural $\log$.

\section{H4: Involvement in an enduring international rivalry will result in state leaders allocating fewer expenditures to public health.}

International wars are likely to have major short- and long-term impacts on public health spending. We cannot, however, investigate those effects here. By standard criteria there were only two international wars during the 1990s; that is, the Gulf War 1990-1991 and Kosovo 1999. This is not enough to give us reliable estimates of the effect of international wars on national health performance, more so as the human effects were vastly compounded by the economic sanctions against Iraq and Serbia before and after those wars. To provide an international conflict dimension we turn to international rivalries, an indicator of conflict and security threats that may cause states to shift resources from health. We expect that during an enduring international rivalry with repeated threats or use of force short of war, public spending will be diverted from social welfare programs-including health - to military purposes (e.g., Ball, 1988; Mintz, 1989; World Bank, 1993; Fitzsimmons and Whiteside, 1994:25-26; UNDP, 1994; Chan, 1995; Adeola, 1996; Yildirim and Sezgin, 2002).

An enduring international rivalry is defined as a relationship between two states experiencing at least 6 militarized international disputes during a 20-year period, and in which fewer than 11 years have elapsed since the last dispute. We extend data from Diehl and Goertz (2000) to recent years from Wallensteen and Sollenberg (2000). We code as 1 each of the 25 countries involved in an enduring international rivalry during 1989-1997, and all others as 0. 
We conclude with two hypotheses about basic economic and social factors used in analyses by the WHO and health economists (Filmer and Pritchett, 1999; Evans et al., 2000a).

\section{H5: Higher per capita incomes will result in state leaders allocating more expenditures to public health. \\ H6: Higher levels of education in society will result in state leaders allocating more expenditures to public health.}

The higher the level of per capita income, the more tax revenues that are potentially available to spend on the health of the public without producing acute trade-offs between health spending and other state-funded programs. The more educated the population, the better informed it is likely to be about the potential benefits of various programs and expenditures, and thus to call for and support greater public inputs to the health care system.

Gross Domestic Product (GDP) per capita is measured for 1998 in PPP-adjusted \$ (U. S. Central Intelligence Agency, 1999) and its range is from $\$ 530$ (Sierra Leone) to $\$ 32,700$ (Luxembourg), with a median of $\$ 3,500$ (Jordan). We use the natural logarithm of GDP per capita to reduce skewness. For the measurement of education levels in society, we follow the lead of WHO analysts, which use the level of educational attainment. WHO regards average level of schooling in the adult population as the most widely available and sensitive measure, logged to correct skewness and to reflect the declining marginal impact of education. ${ }^{2}$ For 1998 it ranges from 1.04 years of education (Mali) to 11.5 (United States), with a median of 6.03 (Costa Rica).

\section{Empirical Results for the Allocation of Resources to Public Health}

We test these hypotheses using ordinary least squares regression on data for 179 countries: nearly all the 191 members of the WHO, omitting only small states lacking data on one or more of the explanatory variables. ${ }^{3}$ Table 1 shows the results for public health expenditures as a percentage of GDP. The columns show, respectively: 1) the estimated coefficients, 2) the standard errors, 3), the probability levels, ${ }^{4}$ and 4) through 7) the actual change in value of the dependent variable and the percentage change from the median value by moving each explanatory variable to the $5^{\text {th }}$ and $95^{\text {th }}$ percentiles.

All political hypotheses are supported, with significant coefficients and important substantive effects. Throughout the Polity scale democracies spend more on their citizens' health than do autocracies. Controlling for all other factors, a democratic government at the $95^{\text {th }}$ percentile on the Polity scale allocated about $49 \%$ more to health than did a dictatorship at the $5^{\text {th }}$ percentile on the Polity score. For instance, the relatively democratic Philippine government spent more than twice as much per capita on public health as did Suharto-led Indonesia, despite the two countries' roughly similar income per capita. Income inequality sharply reduces public health spending (a $23 \%$ drop from the median to the $95^{\text {th }}$ percentile of inequality). Nigeria has high income inequality at .481 and only $0.9 \%$ of GDP is spent on public health, while Ghana's income Gini is more equal at 0.317 and $1.4 \%$ of Ghana's GDP goes to public health. Ethnic heterogeneity also makes a big difference, especially toward the homogeneous end of the scale (the $5^{\text {th }}$ percentile on heterogeneity shows $11 \%$

\footnotetext{
${ }^{2}$ Some observations were estimated by multiple imputation from other data on educational attainment. For sources and methods see Evans et al. (2000b).

${ }^{3}$ For the two equations below the $\mathrm{N}$ varies by 1 in either direction because of missing data on expenditures. We have also examined instances where collinearity might be a problem, and found none in any of the equations we tested. The highest correlation among any pair of independent variables used in a single equation is only 0.7 , for education and GDP per capita.

${ }^{4}$ Since all our hypotheses specify a direction of relationship, the p-values are for one-tailed tests.
} 


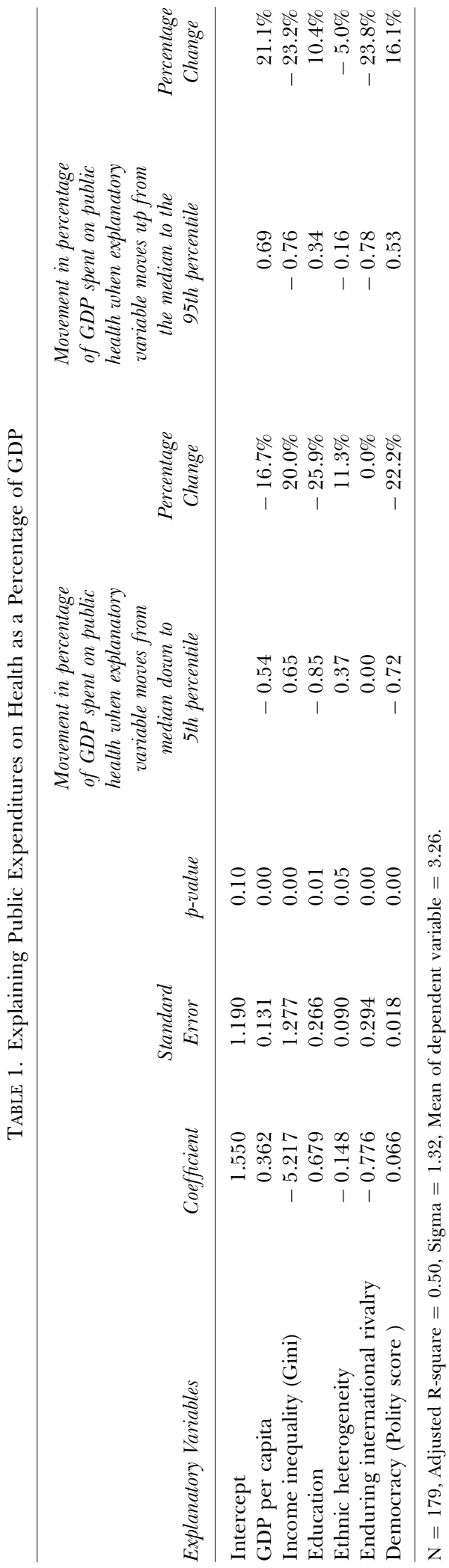


higher spending than the median). Bangladesh, ethnically homogeneous but impoverished, allocates $2.2 \%$ to health while Ethiopia, similarly poor but more heterogeneous, allocates just $1.4 \%$. An enduring international rivalry also depresses public health expenditures and the substantive impact is large, producing a $24 \%$ reduction in public funds allocated to health. For instance, Pakistan and Syria, with relatively high levels of defense spending, allocate less than 1\% of GDP to public health.

The two control variables from standard public health models have a powerful effect. GDP per capita has a substantial impact, especially among richer countries (21\% higher in the $95^{\text {th }}$ percentile than at the median). The average level of education also makes a big difference, especially toward the low end, near the $5^{\text {th }}$ percentile.

Overall, we find that domestic and international politics play an important role in shaping government decisions to allocate resources to public health programs. The next step is to use public health spending as an explanatory variable in an equation to explain overall levels of total health care spending.

\section{Hypotheses on Total Levels of Health Spending}

Our second equation represents a simple model to account for total health expenditures per capita. Total spending per capita (1998) ranges from $\$ 4,055$ (United States) to $\$ 11$ (Somalia), with a median of $\$ 197$ (Thailand). WHO declares that it is very hard for countries to provide good health outputs below a total expenditure of about $\$ 60$ per capita, and that it would cost just $\$ 6$ billion per year to bring up to this threshold the 41 countries with lower expenditures (Evans et al., 2000a:24). As these distributions are skewed we use natural logarithms.

The analytical focus is now on the overall level of financial resources committed to the health care system. We draw on standard analyses by economists and public health experts to formulate several hypotheses. In this model the effect of the political influences is captured indirectly by including public health expenditures as a percentage of GDP as an explanatory variable. We had no theoretically compelling hypotheses for why those political variables would exert a strong direct impact on private health expenditures. ${ }^{5}$

H7: Higher per capita incomes will result in higher total health expenditures.

H8: Higher levels of education in society will result in higher total health expenditures.

As previously argued, the higher the level of per capita income in society, the greater the tax revenues available for public spending on health by governments. Furthermore, higher levels of income and wealth should also enable individuals and businesses to afford to spend more on private health care. Again following WHO practice, we also expect that higher education levels in society would be associated with greater support and interest in achieving high health standards through support of both public and private spending on various health care programs. For both income and levels of education we use the same measures as in the first equation.

H9: Higher allocations of private spending to health care will result in higher total health expenditures.

H10: Higher allocations of public spending to health care will result in higher total health expenditures.

\footnotetext{
${ }^{5}$ Nor is there much evidence that they do. Public and private health spending in part substitute for each other. They are weakly correlated, at -0.1 . In an expanded equation to explain private health spending only two political variables, income inequality and enduring rivalry, are even weakly significant $(\mathrm{p}=$ about .05$)$. And only those two are significant in an expanded equation for total health spending ( $\mathrm{p}=$ just under .10).
} 
These two hypotheses reflect the straightforward relationship that in societies where both public and private actors make decisions to allocate a larger percentage of available resources to health care, the overall level of total health spending should be greater. Thus while $\mathrm{H} 7$ posits that wealthy societies can afford to spend more on health care, $\mathrm{H} 9$ and $\mathrm{H} 10$ point out that there are always competing claims in society on how to spend available resources. As a result, public and private decisions to spend more or less on health relative to other programs help determine the overall amount of resources spent on maintaining and improving heath care. We use the same source for private health spending as for public spending, and sum them. Private health spending ranges from $0.3 \%$ (Kuwait) of GDP to $8.8 \%$ (Lebanon) with a median at $1.9 \%$ (Oman).

\section{Empirical Results for Total Levels of Health Spending}

Table 2 reports the results in the same format as in Table 1. All hypotheses are supported with significant coefficients that produce moderate to large substantive effects. ${ }^{6}$ GDP per capita has a powerful impact. For example, the shift from the median GDP of approximately $\$ 5,000$ per capita to the $95^{\text {th }}$ percentile GDP of $\$ 22,700$ per capita produces an increase of $\$ 1,028$ in total health spending per capita. Education also produces strong effects as the movement from 6.5 years of average education to 10.2 years is associated with an $11 \%$ increase in total health spending per capita. Both of these findings converge with standard analyses by economists and public health experts (Filmer and Pritchett, 1999; Evans et al., 2000a). Finally, higher allocations of public or private resources to health spending are strongly and positively associated with overall total health spending levels. Since public spending usually constitutes a larger portion of total spending, the marginal impact of allocating public spending is greater, as shown in the table.

This second set of results is important. First, as we show below, total health expenditures per capita is a powerful variable in accounting for overall health outcomes on a cross-national basis, so we need to understand what affects it. Second, it shows that allocation of public spending to health expenditures is a major contributor to total health expenditures per capita, and we have already shown (Table 1) that public spending on health is a function of several political variables. The critical point then is that political variables have important but indirect impacts on health performance through their causal linkage to public health spending.

\section{Theoretical Analysis of the Causes of National Health Performance}

We now turn to the centerpiece of our analysis, in which we examine the level of health achievement in a population. Our dependent variable is HALE, the WHO measure for health-adjusted life expectancy at age zero, discussed at the beginning of the article. We present several new hypotheses about the direct impact of political variables on HALEs, and include variables from basic WHO models as additional explanatory variables. Our first three hypotheses share a common logic about domestic political variables, linking limited access to health services and greater exposure to health risk factors to lower HALE scores.

\section{H11: The more unequal the distribution of income, the lower will be the HALE.}

\footnotetext{
${ }^{6}$ While still very good at 0.50 , the adjusted R-square for the allocation of resources to public health in Table 1 is substantially lower than the 0.97 for the equation explaining total levels of health spending in Table 2 and 0.81 for the equation explaining total levels of health performance in Table 3 . This apparent weakness is largely because the allocation variable is a ratio rather than an absolute level. Imprecise measurement can play a bigger role with ratios, as they are likely to be more volatile in any single cross-section.
} 


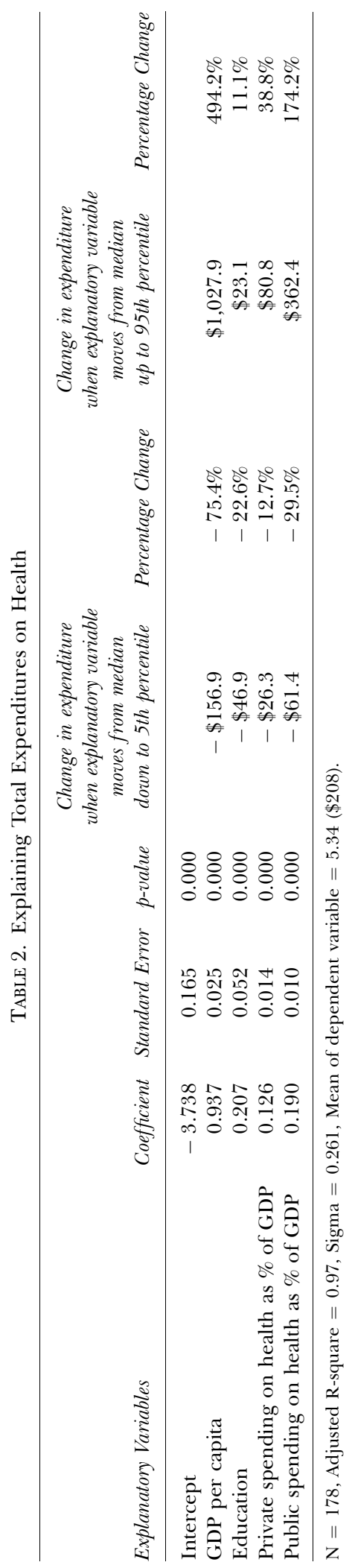


While we have already posited that income inequality indirectly impacts on health performance by influencing allocation decisions on public health expenditures (see H2), we also hypothesize a more direct effect as well. That is, the more unequal the distribution of income, the more unequal will be the distribution of access to both public and private health care facilities. The provision of high quality health care services is thus limited to a smaller segment of the general population, producing lower overall levels of health performance. The rich get more access - at low marginal utility, and the poor get less access - at a level of income at which the marginal utility of greater access would be high. As a result, the poorer segments of the population already at greater risk to disease, disability, and death fail to receive necessary health care services, producing aggregate patterns that produce lower HALE scores.

\section{H12: The more ethnically/linguistically/religiously diverse the population, the lower will be the HALE.}

As we argued above, ethnic differences often result in discrimination and unequal access to political power. Once again, group cleavages in society not only indirectly impact on health conditions through the allocation of public spending on health (see H3), but also directly affect health performance by limiting access to the health care system. Access to health services will be biased in favor of politically dominant ethnic groups in society, and politically weak minorities will suffer from limited access to health services. Consequently, minority groups that are already exposed to greater health risks due to discrimination in housing, education, and job opportunities will lack sufficient support from the health care system.

\section{H13: The faster the pace of urbanization the lower will be the HALE.}

Fast-paced urbanization, particularly in low- and middle-income countries, often brings poor new urban dwellers into slums where they are exposed to new disease vectors and other increased health risks. They will lack adequate access to care as the supply of health service lags behind the surge in need. Surveillance, immunization, and the provision of safe water all become more difficult. Rapid urbanization often reflects an influx of poor and marginalized people from rural areas-people who are politically weak and thus suffer from inadequate access to health care despite great need. New residents of urban slums are unlikely to be well organized in unions to create effective pressure for services either in the workplace or in politics. They are likely to be under-represented in established political parties that have already developed a base of political support among other urban constituencies. A gap between great need and inadequate health care delivery marks this relative neglect of new city dwellers. Marginal utility analysis predicts that individuals or groups receiving less than an equal share of health care lose more disability-adjusted life expectancy than is gained by individuals or groups receiving more than an equal share of health care. That should be especially true when the disadvantaged group is exposed to the diseases of urban slums.

Our measure of recent urbanization is the average annual percentage change in the urban portion of the population, 1990-1995 (United Nations, 1998:132-135). It ranges from $-0.41 \%$ (Belize) to $7.35 \%$ (Botswana), with a median of $0.88 \%$ (Grenada).

H14: The occurrence and severity of civil wars will reduce the level of HALE. ${ }^{7}$

We expect civil wars to kill and maim people. But that is more than just a tautology. Wars continue to kill people well after the shooting stops. Civil wars do so

\footnotetext{
${ }^{7}$ Ghobarah, Huth, and Russett (2003) analyze the effects of civil wars more extensively.
} 
by destroying health care system infrastructure that cannot rapidly be replaced, by disrupting normal economic activity and health care delivery, and by slowing down the rebuilding of the health care system in the postwar period due to multiple and wide-ranging reconstruction programs in other areas of society (Collier, 1999; see also Stewart, 1993).

Military forces often deliberately target health care facilities in order to weaken the opposition. The result is that the human and fixed capital resources available to support the health care system are depleted. For example, heavy fighting in urban areas is likely to damage or destroy clinics, hospitals, and health care centers; rebuilding this infrastructure is unlikely to be completed quickly in the postwar period as governments face many pressing reconstruction programs. Wartime destruction and disruption of transportation infrastructure (roads, bridges, railroad systems; communications and electricity) also weakens the ability to distribute clean water, food, medicine, and relief supplies, both to refugees and to others who stay in place. As a result, health care systems suffer shortages in supplies and personnel, inadequate facilities, and a reduced capacity to reach populations outside of major urban centers. These shortages and limited access severely strain health care professionals' ability to deliver treatment and aid efficiently into postwar periods. Furthermore, severe civil wars may induce a substantial flight of highly trained medical professionals, and this loss of human capital may not be reversed by their prompt return or replacement by newly trained health workers until long after the wars end.

Civil wars often produce huge movements of persons displaced within their own countries. They often lack clean water, food, and access to health care, and these people may remain displaced for years after the end of the civil war. Thus the very people exposed to high health risk factors simultaneously suffer from limited and inadequate access to health services. For example, in many countries ravaged by civil wars the crude mortality rates among newly arrived refugees were 5 to 12 times above the normal rate. Epidemics of diarrheal diseases, measles, acute respiratory infections, malaria, and other diseases are typical. Malnutrition is common, weakening people's defenses against infection. Civil war has been labeled as the predominant cause of famine in the 1990s. (On much of the above see Toole, 2000.)

Even after the fighting subsides, epidemic diseases may become rampant, extending far beyond the displaced population, and immunization and treatment programs are overwhelmed (Fitzsimmons and Whiteside, 1994). Non-displaced populations may also be at greater risk following severe civil wars. For example, diseases that become rampant in camps for displaced populations may easily spread to other regions. Prevention and treatment programs already weakened by the destruction of health care infrastructure during civil wars become overwhelmed as new strains of infectious disease bloom. These spreading diseases may be especially damaging to children, given their greater susceptibility to infection. For example, efforts to eradicate Guinea worm, river blindness, and polio, successful in most countries, have been severely disrupted in states experiencing the most intense civil wars. Drug-resistant strains of tuberculosis can develop and in turn weaken resistance to other diseases, and it is commonly held that the spread of AIDS in Africa has been greatly increased by refugee population movements associated with civil wars (Reid, 1998; Epstein, 2002). Finally, the risk of physical violence is likely to increase in the aftermath of long and severe civil wars, based on changes in individual and social psychology (Bracken and Petty, 1998). Homicide and other crime rates rise during international wars, tending to peak in the first year after the war. The experience of war makes the use of violence within states more common (Archer and Gartner, 1976; Stein, 1980). Gerosi and King (2002) report a significant rise in homicides and suicides, transportation deaths, and other unintentional injuries (both of the latter are likely to include misclassed suicides) in the U.S. population immediately following the Korean and Vietnam wars. If 
international war has this effect, we should certainly expect the direct and immediate experience of civil war to do the same. These social and psychological changes are magnified by the widespread availability of small arms after many civil wars and the relative weakness of many state police forces compared to private security forces.

H15: Civil war in a geographically contiguous country will lower the HALE.

Whereas many displaced persons stay in their own countries during civil wars, others flee across national borders to become international refugees: their own countries lack the means to care for them, and they often are fleeing political or ethnic persecution from those who have the upper hand in the war. The Rwanda civil war generated not only 1.4 million internally displaced persons, but a total of 1.5 million refugees into neighboring Zaire, Tanzania, and Burundi (Toole, 2000:98). Large-scale refugee movements can produce adverse health consequences for neighboring countries in two ways. First, if the refugees must be cared for mainly by the medical resources of the receiving country, those resources may be diverted from care of the host country's own population. Second, they can bring infectious diseases associated with the disruptions of war and the poor living conditions in which they find themselves in host countries. Refugee camps can become vectors for transmitting infectious diseases to the host population.

For H14, deaths from civil war in the years 1991 to 1997 represents a measure of both the existence and severity of civil war, expressed as the number of deaths per 100 people in the country to measure the war's intensity. Civil wars are defined as armed conflicts producing 1,000 or more fatalities per year among regular armed forces, rebel forces, and civilians directly targeted by either. Civil war years and fatality figures are derived from leading data sets on civil war compiled by scholars (COW data on civil wars website: http://www.umich.edu/ cowproj/; Licklider, 1995; Regan, 2000; Doyle and Sambanis, 2000; Wallensteen and Sollenberg, 2000). For most countries its value is 0 ; for the 34 countries experiencing civil war during the period it ranges from .02 to 96.9 (Rwanda). For H15, we simply use a dummy variable coded as 1 if any contiguous state experienced a civil war from 1989 to 1998. Contiguity is defined as sharing a land border or separated by no more than 12 miles of water.

The last hypotheses draw on standard WHO models of cross-national health performance.

\section{H16: The higher the level of total health expenditures per capita the higher will be the HALE.}

Higher income improves health through public and private decisions to spend money on hospitals, preventive and curative care, sanitation, and nutrition. Earlier work by economists such as Pritchett and Summers (1996) showed that "wealthier is healthier." We build on their work with a wider set of countries and a finer-grained argument about how total income leads to better health. Per capita GDP does not directly determine the production of health outputs. Rather, it permits a high level of expenditure for health purposes, and though highly collinear with income $(\mathrm{r}=0.90)$, health spending is also influenced by political processes and institutions. For example, above we found that democracy has a strong impact on total health expenditures by raising public health spending. And spending is distributed in a political process that produces actual health outcomes. So our two-stage model, in the economics tradition of production function analysis, treats income as an uncontrollable variable outside the direct process that brings good public health outputs. We follow the WHO (Evans et al., 2000a:13) in using total health expenditure per capita as a theoretically satisfying variable to incorporate prior political processes that affect spending. It includes health services and prevention, 
but not the provision of clean water and sanitation that are also affected by levels of education and income.

\section{H17: The more educated the population the higher will be the HALE.}

At higher levels of education, preventive and treatment programs become more widespread and effective. Demand for better health care increases as does more knowledgeable and effective consumption throughout the population. Education is strongly associated with the health of both children and adults in rich and poor countries. It is the other independent variable, with total health spending, in WHO analyses of health attainment (Evans et al., 2000a:13). ${ }^{8}$

\section{Empirical Results for Influences on Health Performance}

Table 3 shows the results for the HALE equation in the same format as previous tables. The strongest impact, not surprisingly, is from the level of total health spending - with a shift from the median to the $95^{\text {th }}$ percentile bringing 10 years of additional healthy life. The coefficient for ethnic heterogeneity is barely significant, but produces some substantive effect: moving from the median of the heterogeneity index to a quite homogenous $5^{\text {th }}$ percentile brings HALE more than a year higher. This direct effect reinforces the separate stronger negative impact of ethnic diversity on the allocation of public health expenditures. Together, these results suggest that ethnic diversity operates to diminish the overall level of health achievement primarily by reducing overall expenditures, and to a lesser extent also through some discrimination in the distribution of those expenditures and hence access to health care.

The impact of income inequality on HALE is highly significant and substantively strong. A shift from the median Gini index to the $95^{\text {th }}$ percentile reduces average healthy life expectancy in that country by over 2 years. This is in addition to the separate impact of income inequality on HALE through reducing the allocation to public health expenditures. Together, these results indicate a substantial impact of income inequality on health conditions (HALE) that operates both through lowering public health expenditures and through discrimination in the distribution of those expenditures, and hence on access to health care services. It is important to also recognize that the indirect negative impact of income inequality on HALE through lowering public health expenditures is not adequately compensated by private health spending. Even controlling for total health spending, in unequal societies the overall level of life expectancy is lower and the level of disability is higher.

The United States provides an example for both the above findings. It is moderately diverse in ethnic composition (86 countries are more homogeneous) and distinctly low in economic equality (108 countries are more equal). Despite being the richest country on the globe and the biggest total spender per capita on health care, 27 countries have better HALE.

The impact of education is also strong, especially among poorer countries. If Benin somehow could provide its people with an average of 6 years of schooling instead of the actual 1.7 years; that is, if it were at the median level of schooling rather than at the $5^{\text {th }}$ percentile from the bottom, we would expect its citizens to

\footnotetext{
${ }^{8}$ Two variables that we hypothesized and found to affect public health spending are not included in this output equation. As we noted in discussing the relevant spending hypothesis, the recent literature indicates that democracy's major impact is in raising public health spending, and thus strongly but largely indirectly affects health outcomes. Similarly we hypothesized that the principal effect of an international rivalry short of war would be fiscal, in reducing public health spending. Also, three of the variables we now hypothesize to affect health outputs did not appear in our equations to explain health spending. We encountered contradictory arguments about the probable effect of civil wars (at home, and in neighboring states) on health spending, and no compelling hypothesis that rapid urbanization would significantly affect spending either way. We have, however, run expanded HALE and spending equations not shown here, and none of these variables, when included, had a statistically significant effect.
} 


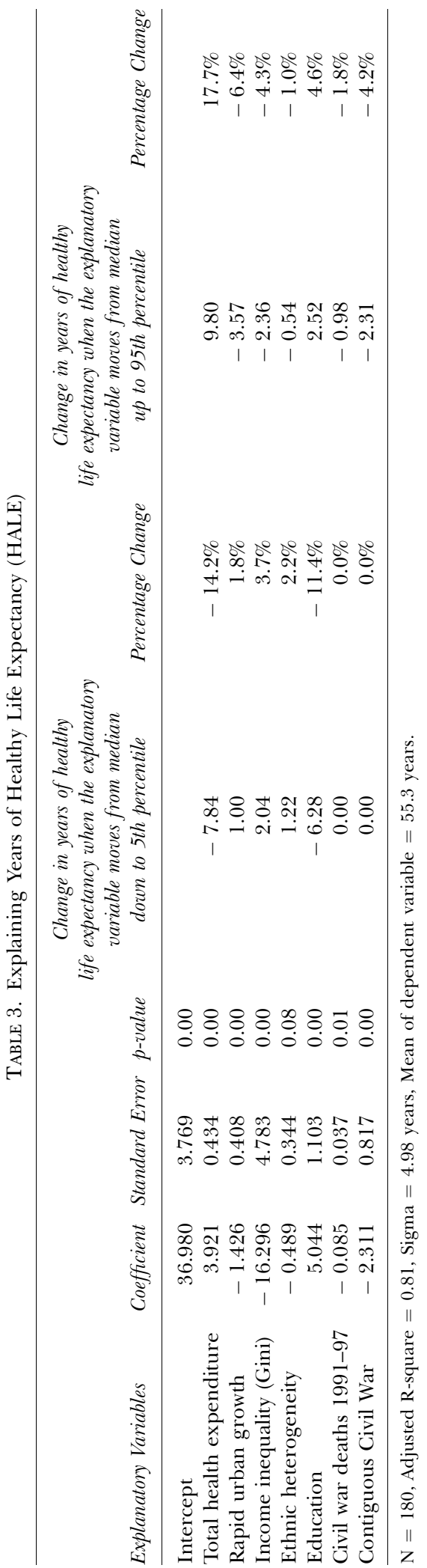


gain over 6 more years of healthy life. Partly that reflects the absence of per capita income in this equation, as education-more highly correlated with income than with health expenditures - likely picks up some effect of income here. Nonetheless, educational attainment was fairly strongly associated with total health spending, and these two results together indicate that education affects both the level of health expenditures and the achievement of better health through greater access and effective use of health services.

A high pace of urbanization also has a strong impact, cutting HALE by over 3 years in the more rapidly urbanizing countries. As we argued, this negative impact is likely to be due to the susceptibility of new urban dwellers to disease and the political weakness of new poor urban residents to ensure that the health care system delivers adequate prevention and treatment to them.

Finally, the matter of civil war. First, civil wars within a country have a clear negative impact on health conditions with the loss of a full year of healthy life at the $95^{\mathrm{th}}$ percentile. Not surprisingly, civil wars do kill people, and not just during the course of the war. ${ }^{9}$ The damage to life and well-being lingers for years after the war is fought, due to the disruption of institutions and the infrastructure. Truly severe civil wars (rare events to be sure) are even more detrimental. These can reduce healthy life expectancy by nearly 10 full years (e.g., Rwanda and Liberia). ${ }^{10}$

Moreover, it is not just civil war in one's own country that matters. A country's HALE is typically depressed by more than 2 years if a neighboring state recently suffered from a civil war. ${ }^{11}$ This relationship is not weakened even if we exclude all countries that themselves experienced a civil war.

Note the cluster of eight countries (Namibia, Zambia, South Africa, Congo-Zaire, Zimbabwe, Malawi, Swaziland, and Lesotho, in declining magnitude of the residual) in southern Africa that are outliers at the left of Figure 2, with predicted HALES 9 to 16 years above their actual achievement. All but Congo were also in the top ten for per capita HIV/AIDS cases in 1999. It is commonly believed that the incidence of AIDS in Africa has been greatly abetted by civil wars (Reid, 1998; Epstein, 2002). None of the eight countries experienced major civil conflict in the 1991-1997 period, but a few (Namibia, South Africa) had civil wars a few years earlier, and the manifestation of HIV infection is often delayed. All of them also border on states that experienced civil wars either in 1991-1997 or somewhat earlier.

Many other explanations have been proposed for the prevalence of AIDS in these countries (UN Program on HIV/AIDS, unaids.org/epidemic_update/report/ index.html). No one or two are satisfactory. Public health researchers do not agree on why AIDS is so common in this region. We do not show an equation that includes an HIV/AIDS variable, since to do so would merely put a label on a disease

\footnotetext{
${ }^{9}$ Suppose civil war kills all but one person in a country during the war, yet that last person is very healthy and is expected to live long. HALE would then drop in the first year due to all the war deaths, but rise in the next year because it is based only on people alive. In fact, however, we see low HALEs for several years after a war, reflecting new deaths and disabilities.

10 Theory does not tell us just what the correct lag should be. For most infectious diseases - which we hypothesize as the principal cause of indirect civil war deaths - the lag time would seem short. Effects of damage to the health care system would probably last longer, and the lag for cancers would be too long and varied for us to reasonably test for it. Experimentation with the lag structure indicates that the coefficient for wars in the 1977-1990 period is only about one-fourth as large as for the 1991-1997 period in our basic equation, and not statistically significant. If we make a break between 1991-1995 and 1996-1997 the impact of the coefficient for the latter period is higher, but the standard error is very much higher. Eliminating all countries whose civil wars extended past 1997 reduces the impact of wars in 1996-1997, but not that of earlier wars. Until more detailed data are available the 1991-1997 lag to the 2000 HALEs seems about right.

${ }^{11}$ The metrics are only approximately comparable between the continuous civil war variable and the dummy variable for presence of a civil war in an adjacent state. One death from civil war per 100 people represents the $95^{\text {th }}$ percentile of civil war deaths (34 countries out of 177 experienced civil wars, of which 9 were at or above this level of severity, so the comparison is reasonable but underestimates the effect of very severe civil wars at home).
} 


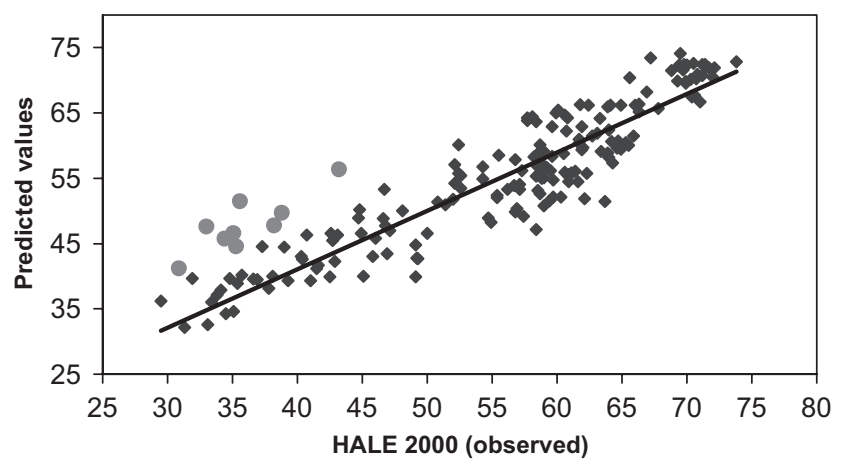

FIG. 2.

without providing a socioeconomic explanation of its prevalence. ${ }^{12}$ This concurs with Evans et al. (2000a:22), who decline to use an HIV variable to predict HALE as a measure of efficiency of the health system. Their view, and ours, is that the health system should be held at least partly accountable for the failure to control AIDS.

\section{Conclusions, Limitations, and Future Research}

In trying to explain expenditure inputs into the health system, and outputs in the form of the reduction of human misery, we combined variables commonly used by public health analysts with economic, social, and political influences much less commonly studied in this context. The phenomena we tried to explain were measured by newly available cross-national data from WHO. Though preliminary, the results showed the utility of modeling health expenditures and then using those expenditures as an explanatory variable for achievement in health care. Forecasting as well as explanation can benefit. Politics matters, in ways that illuminate the subfields of both comparative politics and international relations as well as public health.

The models we use to explain variation in the allocation of public spending on health care show that, in addition to income and education, several political influences matter. For example, the degree of democracy in a country is strongly associated with higher allocation levels. We also found that ethnically diverse countries and those experiencing great income inequality show significantly lower levels of spending allocated to public health. Furthermore, countries engaged in enduring international rivalries allocate lower levels of public spending to health. Our findings help to quantify these influences and to assess their relative impact.

When we moved to explaining outputs of the health system, the patterns were similar in some respects but importantly different in others. Total health expenditures per capita strongly raise the level of disability-adjusted life expectancy, as does education. As expected, the direct negative effects of civil wars and rapid urbanization on HALE are strong. Income inequality strongly depresses HALEs more by its indirect effect in reducing public health spending than by its direct effect. The primary effect of ethnic heterogeneity works indirectly by lowering public health spending, but also impacts directly on HALE. Working through different causal routes, both show what happens when groups and segments of the population have little political power.

\footnotetext{
${ }^{12}$ If a variable for the adult HIV rate in 1999 is added, it is highly significant and raises the predictive power of the equation. The explanatory variables that lose power do offer some hints as to what may be behind the AIDS effect: the rate of urbanization becomes statistically insignificant, and the significance level of income inequality drops to $\mathrm{p}=.08$. Inequality and rapid urbanization may well promote HIV/AIDS, but we cannot establish a causal effect here.
} 
This examination of some of the causes of human misery and its alleviation is still in an early stage. Better time-series information is needed to permit stronger causal inferences. Improved data are essential — and are likely to be forthcoming over the next few years. Certainly we need to better comprehend micro-level political and social processes. For example, variation in the health conditions of women and how politics influences health care opportunities for women requires careful analysis. Here we have emphasized health (spending and output) as the phenomenon to be explained, and lagged our explanatory variables accordingly. But poor health conditions surely contribute to economic stagnation, and very likely to civil unrest. Also, democracy may have additional indirect effects on health. We focused on democracy's impact on allocating public spending to health care but there may be further links to educational levels, minority and women's rights, political peace and stability, and economic growth. A more satisfying understanding doubtless requires modeling these reciprocal causal effects beyond what can be done in a single article. ${ }^{13}$ Finally, while we have considered international security threats in our analyses, another large international influence on health conditions may be the process of economic globalization and its possible impact on societal inequalities.

One possibility for research (Ghobarah, Huth, and Russett, 2003) has been to employ a new data set from WHO on so-called DALYs - that is, disability-adjusted life years lost from various particular diseases and conditions, applied separately to both genders and various age groups. In time this will allow us to better estimate the correct time lags, and to focus much more effectively; for example, on the effect of civil wars or income inequality on women and children, and on the burden imposed by particular diseases. Some of these data are discussed in WHO (2000), and more are becoming available. The result should be a far deeper understanding of which groups are especially afflicted, how, and why.

\section{References}

Adeola, F. (1996) Military Expenditures, Health, and Education. Armed Forces and Society 22:441-455. Archer, D., and R. Gartner (1976) Violent Acts and Violent Times: A Comparative Approach to Postwar Homicide Rates. American Sociological Review 41:937-963.

Ball, N. (1988) Security and Economy in the Third World. Princeton, NJ: Princeton University Press.

Bracken, P., And C. Petty (1998) Rethinking the Trauma of War. London: Free Association Books.

Bueno de Mesquita, B., J. Morrow, R. Siverson, And A. Smith (1999) An Institutional Explanation of the Democratic Peace. American Political Science Review 93:791-807.

Chan, S. (1995) Grasping the Peace Dividend: Some Propositions on the Conversion of Swords into Plowshares. Mershon International Studies Review 39(supplement 1):53-95.

Collier, P. (1999) On the Economic Consequences of Civil War. Oxford Economic Papers 51:168-183. Cutler, D. M., And E. Richardson (1997) Measuring the Health of the United States Population. Brookings Papers on Economic Activity-Microeconomics 1997: 217-271.

Dasgupta, P. (1993) An Inquiry into Well-Being and Destitution. New York: Oxford University Press.

Davis, D., AND J. Kuritsky (2002) "Violent Conflict and Its Impact on Health Indicators in SubSaharan Africa, 1980 to 1997." Paper presented at the Annual Meeting of the International Studies Association, New Orleans, March.

Diehl, P., AND G. Goertz (2000) War and Peace in International Rivalry. Ann Arbor: University of Michigan Press.

Diener, E., D. Wirtz, And S. Oishi (2001) End Effects of Rated Life Quality: The James Dean Effect. Psychological Science 12:124-128.

\footnotetext{
${ }^{13}$ While we intend in future work to use simultaneous equations to estimate these effects, we currently lack the instrumental variables needed to ensure the effects estimated by 2- or 3-Stage Least Squares are reliable and robust to different instrumental variables and moderate changes in model specification. The advantage of 2- or 3-Stage Least Squares would be to increase the efficiency of the estimated standard errors (i.e., to reduce the standard errors). As a result, the findings we report in this article are based on a conservative test of our central hypotheses linking political variables to public health. We are encouraged therefore by the generally strong results we have uncovered despite a conservative approach to statistical testing.
} 
Doyle, M., And N. Sambanis (2000) International Peacebuilding: A Theoretical and Quantitative Analysis. American Political Science Review 94:779-803.

EpsteIn, H. (2002) AIDS: The Lesson of Uganda. New York Review of Books 48:18-23.

Evans, D. B., A. Tandon, C. J. L. Murray, and J. A. Lauder (2000a) "The Comparative Efficiency of National Health Systems in Producing Health: An Analysis of 191 Countries." GPE Discussion Paper no. 29. Geneva: WHO.

Evans, D. B., L. Bendib, A. Tandon, J. Lauer, S. Ebenezer, R. C. W. Hutubessy, Y. Asada, and C. J. L. Murray (2000b) "Estimates of Income Per Capita, Literacy, Educational Attainment, Absolute Poverty, and Income Gini Coefficients for the World Health Report 2000." Global Programme on Evidence for Health Policy Discussion Paper no. 7. Geneva: WHO.

Filmer, D., And L. Pritchett (1999) The Impact of Public Spending on Health: Does Money Matter? Social Science E Medicine 49:1309-1323.

Fitzsimmons, D. W., And A. W. Whiteside (1994) Conflict, War, and Public Health. Conflict Studies 276. Research Institute for the Study of Conflict and Terrorism, London.

Foege, W. (2000) "Arms and Public Health: A Global Perspective." In War and Public Health, 2nd ed., edited by B. S. Levy and V. Sidel, pp. 3-11. Washington, DC: American Public Health Association.

GAKIDOU, E., AND G. KING (2002) Measuring Total Health Inequality: Adding Individual Variation to Group-level Differences. International Journal for Equity in Health 1(3).

Garrett, L. (2001) “The Return of Infectious Disease.” In Plague and Politics, edited by A. T. PriceSmith, pp. 183-194. New York: Palgrave.

Gerosi, F., AND G. King (2002) "Short Term Effects of War Deaths on Public Health in the U.S". Cambridge, MA: Harvard Center for Basic Research in the Social Sciences.

Ghobarah, H. A., P. Huth, And B. Russett (2003) Civil Wars Kill and Maim People-Long after the Shooting Stops. American Political Science Review 96:1-14.

Gurr, T. R. (1993) Minorities at Risk: A Global View of Ethnopolitical Conflict. Washington, DC: United States Institute of Peace.

Gurr, T. R. (2000) Peoples versus States: Minorities at Risk in the New Century. Washington, DC: United States Institute of Peace.

King, G., And C. J. L. Murray (2002) Rethinking Human Security. Political Science Quarterly 116:585610.

Lake, D., And M. Baum (2001) The Invisible Hand of Democracy: Political Control and the Provision of Public Services. Comparative Political Studies 87:624-638.

Licklider, R. (1995) The Consequences of Negotiated Settlements in Civil Wars, 1945-1993. American Political Science Review 89:681-690.

MaOZ, Z., AND B. RussetT (1993) Normative and Structural Causes of Democratic Peace, 1946-1986. American Political Science Review 87:624-638.

Mathers, C. D., R. Sadana, J. A. Salomon, C. J. L. Murray, and A. D. Lopez (2000) "Estimates of DALE for 191 Countries: Methods and Results." Global Programme on Evidence for Health Policy (GPE) Working Paper no. 16. Geneva: WHO.

Mintz, A. (1989) Guns Versus Butter. American Political Science Review 83:1285-1293.

Moon, B. (1991) The Political Economy of Basic Human Needs. Ithaca, NY: Cornell University Press.

Moon, B., And W. Dixon (1992) Basic Needs and Growth-Welfare Trade-offs. International Studies Quarterly 36:191-212.

Murray, C., AND A. Lopez (1996) The Global Burden of Disease. Cambridge, MA: Harvard School of Public Health on behalf of the WHO and the World Bank.

Murray, C., And A. Lopez (2000) Progress and Directions in Refining the Global Burden of Disease Approach: A Response to Williams. Health Economics 9:69-82.

Olson, M. (1993) Dictatorship, Democracy, and Development. American Political Science Review 87:567-576.

Pouillier, J. P., And P. Hernandez (2000) "Estimates of National Health Accounts: Aggregates for 191 Countries in 1997.” GPE Discussion Paper no. 26. Geneva: WHO.

Price-Smith, A. (2002) The Health of Nations. Cambridge, MA: M.I.T. Press.

Pritchett, L., AND L. Summers (1996) Wealthier Is Healthier. Journal of Human Resources 31:841-868.

Przeworski, A. M., A. J. A. Cheibub, And F. Limongi (2000) Democracy and Development: Political Institutions and Well-Being in the World, 1950-1990. Cambridge: Cambridge University Press.

REID, E. (1998) “A Future, If One Is Still Alive: The Challenge of the HIV Epidemic.” In Hard Choices: Moral Dilemmas in Humanitarian Intervention, edited by J. Moore, pp. 269-286. Lanham, MD: Rowman \& Littlefield.

Regan, P. (2000) Civil Wars and Foreign Powers. Ann Arbor: University of Michigan Press. 
RussetT, B. (1978) The Marginal Utility of Income Transfers to the Third World. International Organization 32:913-928.

Russett, B., S. Jackson, D. Snidal, And D. Sylvan (1981) Health and Population Patterns as Indicators of Income Inequality. Economic Development and Cultural Change 29:759-779.

SEn, A. (1981) Poverty and Famine. New York: Oxford University Press.

Sen, A., And J. Dreze (1999) The Amartya Sen and Jean Dreze Omnibus. New York: Oxford University Press.

ShaH, G. (1997) Public Health and Urban Development. London: Sage.

Stein, A. A. (1980) The Nation at War. Baltimore, MD: Johns Hopkins University Press.

STEwart, F. (1993) War and Underdevelopment: Can Economic Analysis Help Reduce the Costs? Journal of International Development 5:357-380.

Szreter, S. (2001) "Economic Growth, Disruption, Deprivation, Disease, and Death." In Plague and Politics, edited by A. T. Price-Smith, pp. 76-116. New York: Palgrave.

Toole, M. J. (2000) “Displaced Persons and War." In War and Public Health, 2nd ed., edited by B. Levy and V. Sidel, pp. 197-212. Washington, DC: American Public Health Association.

United Nations (1998) World Urbanization Prospects: The 1996 Revision. New York: United Nations.

United Nations Development Programme (1994) Human Development Report, 1994. New York: United Nations.

Vanhanen, T. (1999) Domestic Ethnic Conflict and Ethnic Nepotism: A Comparative Analysis. Journal of Peace Research 36:55-73.

Wallensteen, P., And M. Sollenberg (2000) Armed Conflict, 1989-99. Journal of Peace Research 37:635-649.

Wilkinson, R. (1996) Unhealthy Societies: The Afflictions of Inequality. New York: Routledge.

Williams, A. (1999) Calculating the Gobal Burden of Disease: Time for a Strategic Reappraisal? Health Economics 8:18.

World Bank (1993) World Bank Development Report 1993: Investing in Health. New York: Oxford University Press.

World Health Organization (2000) The World Health Report 2000: Health Systems: Improving Performance. Geneva: WHO.

World Health Organization (2001) The World Health Report 2001: Health Systems: Improving Performance. Geneva: WHO.

Yildirim, J., AND S. Sezgin (2002) Defense, Education and Health Expenditures in Turkey, 1924-96. Journal of Peace Research 39:569-580.

Zweifel, T., And P. Navia (2000) Democracy, Dictatorship, and Infant Mortality. Journal of Democracy 11:99-114. 